\title{
Microstructures of Reduced Graphene Oxide/Sulfur Nanocomposites and Their Impacts on Lithium Storage Performances
}

\author{
Aaron J. Blake, ${ }^{1}$ Kevin Dorney, ${ }^{2}$ Ioana E. Sizemore, ${ }^{2}$ and Hong Huang ${ }^{1}$ \\ ${ }^{1}$ Department of Mechanical and Materials Engineering, Wright State University, 3640 Colonel Glenn Highway, \\ Dayton, OH 45435, USA \\ ${ }^{2}$ Department of Chemistry, Wright State University, 3640 Colonel Glenn Highway, Dayton, OH 45435, USA
}

Correspondence should be addressed to Hong Huang; hong.huang@wright.edu

Received 21 October 2015; Accepted 10 December 2015

Academic Editor: Chuilin Lai

Copyright (C) 2015 Aaron J. Blake et al. This is an open access article distributed under the Creative Commons Attribution License, which permits unrestricted use, distribution, and reproduction in any medium, provided the original work is properly cited.

\begin{abstract}
The lithium-sulfur (Li/S) concept has a theoretical specific capacity of $1672 \mathrm{mAh} \mathrm{g}^{-1}$ based on the complete reduction of S into lithium sulfide $\left(\mathrm{Li}_{2} \mathrm{~S}\right)$. Practically, however, a pure $\mathrm{S}$ electrode encounters low deliverable capacity and poor charge/discharge cycle life owing to S's electrical insulation and problems associated with polysulfide dissolution. Here, we report our studies to couple $\mathrm{S}$ with reduced graphene oxide ( $\mathrm{rGO}$ ) prepared via either mechanical milling or chemical precipitation. The differences of the resulting $\mathrm{rGO} / \mathrm{S}$ composites with respect to morphology, structure, composition, and phase transformations are extensively studied. Thermal analyses, X-ray diffraction, scanning electron microscopy, and Raman spectroscopic results on the chemical rGO/S consistently confirmed the existence of amorphous/nanocrystalline $\mathrm{S}$ and their homogeneous distribution as well as interaction with the rGO microstructure. The electrochemical performances of chemical $\mathrm{rGO} / \mathrm{S}$ revealed a marked improvement in both capacity retention and $\mathrm{S}$ utilization compared to those of the mechanical $\mathrm{rGO} / \mathrm{S}$.
\end{abstract}

\section{Introduction}

Sulfur is an attractive and emerging cathode alternative in lithium batteries for its high theoretical energy density and low cost [1-3]. The Li/S couple, based on the complete reduction of $\mathrm{S}$ to form $\mathrm{Li}_{2} \mathrm{~S}$, has a theoretical specific capacity of $1672 \mathrm{mAh} \mathrm{g}^{-1} \mathrm{~S}$ corresponding to a theoretical specific energy of over $2600 \mathrm{Wh} \mathrm{kg}^{-1}$ [4-6]. However, considerable technological challenges that are attributed to the intrinsic properties of $S$ and lithium sulfide prevent rapid commercialization of $\mathrm{Li} / \mathrm{S}$ batteries. For instance, elemental $\mathrm{S}$ is an electronic insulator by nature, which demands appropriate conducting additives. Secondly, lithium reaction with $S$ occurs via lithium polysulfide $\left(\mathrm{Li}_{2} \mathrm{~S}_{x}\right)$ intermediates, among which the high-order lithium polysulfides $\left(\mathrm{Li}_{2} \mathrm{~S}_{x}, x \geq 4\right)$ are readily dissolved in the commonly used organic electrolyte. While the liquid phase $\mathrm{Li}_{2} \mathrm{~S}_{x}$ facilitates rapid kinetics beneficial to high rate capability, the soluble $\mathrm{Li}_{2} \mathrm{~S}_{x}$ can diffuse through the electrolyte to the $\mathrm{Li}$ anode leading to gradual capacity degradation upon charge/discharge cycling.
Recent efforts have demonstrated success in attenuating the dissolution of $\mathrm{Li}_{2} \mathrm{~S}_{x}$ and overcoming sulfur's insulating problems via embedding $S$ into various carbon-based additives [7], such as mesoporous carbon [8,9], microporous carbons [10], porous or hollow carbon nanofibers [11, 12], nanotubes [13], graphene, and reduced graphene oxide [1428]. Table 1 lists a set of representative graphene/sulfur composites, synthesis approaches, and their electrochemical performance data which were reported lately. It is seen that $\mathrm{S}$ has been incorporated into graphene via ball milling [14], melting/gasification at elevated temperatures [15-20], chemical reaction [21-24], or emulsion in $\mathrm{CS}_{2}$ solution [2527]. Graphene and reduced graphene oxide ( $\mathrm{rGO}$ ) nanosheets have received much attention because (1) they have relatively high electronic conductivities and lithium-ion diffusion coefficients; (2) the ultrathin and flexible nanosheets can accommodate the volume changes of $S$ upon electrochemical cycling; (3) the reactive functional groups on the nanosheets can immobilize $S$ via moderate chemical interaction [28] and act as growth points for $\mathrm{S}$ during charge, thereby diminishing 
TABLE 1: Comparison of a set of reported studies on graphene/sulfur and graphene oxide/sulfur composites with their corresponding electrochemical performances.

\begin{tabular}{|c|c|c|c|c|c|}
\hline Composite & $\begin{array}{l}\text { S content in } \mathrm{G} / \mathrm{S} \\
\text { powder }(\mathrm{wt})\end{array}$ & Electrolyte & $\begin{array}{c}\text { 1st discharge } \\
\text { capacity }\left(\mathrm{mAh} \mathrm{g}^{-1}\right)\end{array}$ & $\begin{array}{l}\text { Capacity at the } n \text {th } \\
\text { cycle }\left(\mathrm{mAh}^{-1}\right)\end{array}$ & Source \\
\hline $\begin{array}{l}\text { TG - a-S } \\
\text { ball milling }\end{array}$ & $\begin{array}{l}73 \mathrm{wt} \% \\
82 \mathrm{wt} \% \\
\end{array}$ & $1 \mathrm{M}$ LiTFSI/DOL/DME & $\begin{array}{c}\text { 1503@0.1C } \\
\text { 835@1C } \\
\end{array}$ & $\begin{array}{l}\text { 615@100th } \\
530 @ 100 \text { th } \\
\end{array}$ & {$[14]$} \\
\hline $\begin{array}{l}\mathrm{rGO}+\mathrm{a}-\mathrm{S} \\
\text { melting infiltration }\end{array}$ & $22 \mathrm{wt} \%$ & $1 \mathrm{M} \mathrm{LiPF}_{6} / \mathrm{EC} / \mathrm{DMC}$ & $1598 @ 0.16 \mathrm{Ag}^{-1}$ & 670@80th & {$[15]$} \\
\hline $\begin{array}{l}\mathrm{TG}+\mathrm{c}-\mathrm{S} \\
\text { melting infiltrating }\end{array}$ & $\begin{array}{l}20 \mathrm{wt} \% \\
40 \mathrm{wt} \% \\
60 \mathrm{wt} \% \\
80 \mathrm{wt} \% \\
\end{array}$ & $1 \mathrm{M}$ LiTFSI/DOL/DME & $\begin{array}{l}\text { 962@0.28 } \mathrm{A} \mathrm{g}^{-1} \\
1021 @ 0.28 \mathrm{~A} \mathrm{~g}^{-1} \\
1210 @ 0.28 \mathrm{~A} \mathrm{~g}^{-1} \\
854 @ 0.28 \mathrm{Ag}^{-1} \\
\end{array}$ & $\begin{array}{l}\text { 602@70th } \\
728 @ 70 \text { th } \\
880 @ 70 \text { th } \\
449 @ 70 \text { th } \\
\end{array}$ & {$[16]$} \\
\hline $\begin{array}{l}\mathrm{TG}+\mathrm{a}-\mathrm{S} \\
\text { melting infiltration }\end{array}$ & 67 wt $\%$ & $\mathrm{~N} / \mathrm{A}$ & $1290 @ 0.025 \mathrm{Ag}^{-1}$ & 421@100th & {$[17]$} \\
\hline $\begin{array}{l}\mathrm{rGO}+\mathrm{S} \\
\text { melting infiltration }\end{array}$ & 66.7 wt $\%$ & $1 \mathrm{M}$ LiTFSI/DOL/DME & 1093@0.2 C & 435@60th & {$[18]$} \\
\hline $\begin{array}{l}\text { TG }+ \text { a-S } \\
\text { rGO coated }\end{array}$ & $63 w t \%$ & $\mathrm{~N} / \mathrm{A}$ & $1588 @ 0.025 \mathrm{Ag}^{-1}$ & 928@100th & {$[17]$} \\
\hline $\begin{array}{l}\mathrm{mGO}+\mathrm{S}+\mathrm{PEG} \\
\mathrm{GO} / \mathrm{CB} \text { wrapped }\end{array}$ & $\begin{array}{c}70 \mathrm{wt} \% \\
(34-46 \%) \\
\end{array}$ & $1 \mathrm{M} \mathrm{LiTFSI/DOL/DME}$ & $960 @ 0.2 \mathrm{C}$ & 520@100th & {$[19]$} \\
\hline $\begin{array}{l}\text { pGNS + a-S } \\
\text { melting infiltration }\end{array}$ & $22 \mathrm{wt} \%$ & $1 \mathrm{M}$ LiTFSI/PEGDME & $1611 @ 0.05 \mathrm{~A} \mathrm{~g}^{-1}$ & 539@40th & {$[20]$} \\
\hline $\begin{array}{l}\text { pGNS }+\mathrm{S} \\
\text { melting infiltration }\end{array}$ & 66.7 wt $\%$ & $1 \mathrm{M}$ LiTFSI/DOL/DME & 1379@0.2 C & 1007@60th & {$[18]$} \\
\hline $\begin{array}{l}\mathrm{rGO}+\mathrm{c}-\mathrm{S} \\
\mathrm{Na}_{2} \mathrm{~S}_{x} \text { oxidation }\end{array}$ & $87 w t \%$ & $\begin{array}{c}\text { 1 M LiTFSI/DOL/ } \\
\text { TEGDME } \\
\end{array}$ & $705 @ 0.33 \mathrm{Ag}^{-1}$ & 492@50th & {$[21]$} \\
\hline $\begin{array}{l}\mathrm{rGO}+\mathrm{c}-\mathrm{S} \\
\mathrm{Na}_{2} \mathrm{~S}+\mathrm{NaSO}_{3}\end{array}$ & $75.2 \mathrm{wt} \%$ & $\begin{array}{c}1 \mathrm{M} \mathrm{LiCF}_{3} \mathrm{SO}_{3}+0.2 \mathrm{wt} \% \\
\mathrm{LiNO}_{3} / \\
\mathrm{DME} / \mathrm{DOL} \\
\end{array}$ & $1300 @ 0.2 \mathrm{Ag}^{-1}$ & 930@50th & {$[22]$} \\
\hline $\begin{array}{l}\mathrm{rGO}+\mathrm{S} \\
\mathrm{Na}_{2} \mathrm{SO}_{3}+\mathrm{Na}_{2} \mathrm{~S}+\mathrm{rGO}\end{array}$ & $\begin{array}{c}63.6 \mathrm{wt} \% \\
50.9 \% \\
\end{array}$ & $1 \mathrm{M}$ LiTFSI/DOL/DME & $1267 @ 0.314 \mathrm{Ag}^{-1}$ & 804@80th & {$[23]$} \\
\hline $\begin{array}{l}\text { p graphene }+\mathrm{c}-\mathrm{S} \\
\mathrm{Na}_{2} \mathrm{~S}_{2} \mathrm{O}_{3}+\mathrm{H}_{2} \mathrm{SO}_{4}\end{array}$ & $\begin{array}{c}83.3 \mathrm{wt} \% \\
66.6 \% \\
\end{array}$ & $\begin{array}{c}\mathrm{M} \mathrm{LiTFSI}+0.1 \mathrm{M} \mathrm{LiNO}_{3} / \\
\text { EGDME/DOXL }\end{array}$ & 1237@0.1C & 810@50th & {$[24]$} \\
\hline $\begin{array}{l}\mathrm{TG}+\mathrm{c}-\mathrm{S} \\
\mathrm{S} \text { dissolve in } \mathrm{CS}_{2} \\
\end{array}$ & $71.8 \mathrm{wt} \%$ & $1 \mathrm{M}$ LiTFSI/DOL/DME & 923@0.1C & 490@50th & {$[25]$} \\
\hline $\begin{array}{l}\mathrm{rGO}+\mathrm{S} \\
\text { chemical microemulsion }\end{array}$ & $66 \mathrm{wt} \%$ & $\begin{array}{c}\mathrm{M} \mathrm{LiTFSI} \mathrm{PYR}_{14} \mathrm{TFSI} / \\
\text { PEGDME }\end{array}$ & $1320 @ 0.168 \mathrm{Ag}^{-1}$ & 735@50th & {$[26]$} \\
\hline $\begin{array}{l}\text { Nafion coated TG + c-S } \\
\text { S dissolve in } \mathrm{CS}_{2}\end{array}$ & 71.8 wt $\%$ & $1 \mathrm{M}$ LiTFSI/DOL/DME & 923@0.1C & 750@50th & {$[25]$} \\
\hline $\begin{array}{l}\mathrm{rGO}+\mathrm{S} \\
\text { wrapped, } \mathrm{S} \text { in } \mathrm{CS}_{2}\end{array}$ & $\begin{array}{c}65 \mathrm{wt} \% \\
(52 \%)\end{array}$ & $1 \mathrm{M}$ LiTFSI/DOL/DME & 725@1 C & 622@60th & {$[27]$} \\
\hline
\end{tabular}

${ }^{*}$ rGO: reduced graphene oxide; TG: thermally exfoliated graphene; pGNS: porous (activated) graphene nanosheets.

${ }^{* *}$ a-S: amorphous sulfur; c-S: crystalline sulfur.

${ }^{* * *}$ In most literatures, the electrode for electrochemical characterizations contains $80 \mathrm{wt} \% \mathrm{GO} / \mathrm{S}, 10 \mathrm{wt} \%$ carbon additive, and $10 \mathrm{wt} \%$ binder.

$\mathrm{Li}_{2} \mathrm{~S}_{x}$ leaching; and (4) ubiquitous cavities can be created on the surface of graphene sheets via oxidation activation to facilitate the intimate electrical contact and S immobilization. Due to the large variety of synthesis conditions, $\mathrm{S}$ compositions, and choice of electrolyte as shown in the table, it is difficult to quantitatively correlate the microstructure of $S$ with electrochemical performances. To this end, the focus of this paper is to report the one-to-one comparison to show the differences of GO/S composites in the aspects of structure, phase, microstructure, and their impacts on lithium storage/removal electrochemical performances. The microstructure of $\mathrm{S}$ is tuned via two distinct compositing approaches, that is, physical mixing via mechanical grinding (MGO/S) and chemical reaction via in situ surface sulfurization $(\mathrm{CGO} / \mathrm{S})$.

The structure and morphology of $\mathrm{MGO} / \mathrm{S}$ and $\mathrm{CGO} / \mathrm{S}$ were analyzed with the help of X-ray diffractometer (XRD) and scanning electron microscopy (SEM). The sulfur contents and their thermal stability were studied with the help of thermogravimetric analysis (TGA) and differential scanning calorimetry (DSC). Raman spectroscopy has emerged as a powerful analytical technique for the microstructural characterization of a variety of graphitic nanocomposites [29-32]. Despite the wealth of information now available 
from a single Raman measurement of a nanographite system, the data obtained from such experiments is limited to the localized carbon structure at the focal point of the laser. Hyperspectral Raman mapping allows the acquisition of Raman spectra across a relatively large region of the sample, which provides for a more representative understanding of the overall specimen. Recent developments in advanced chemometric algorithms, for example, partial least squares (PLS), can greatly simplify the postacquisition data analysis and extraction of structural information [33-36]. In this research, we investigated the chemical state and distribution of $\mathrm{S}$ in $\mathrm{MGO} / \mathrm{S}$ and $\mathrm{CGO} / \mathrm{S}$ with the help of both point and PLS Raman mapping.

\section{Experimental}

2.1. Fabrication of GO/S Composites. The MGO/S composite powders were prepared by mechanically milling the mixture of rGO and S (Aldrich) for 15 minutes with an agate mortar and pestle. The rGO nanosheets were fabricated using the modified Hummer's method, which has been described elsewhere [37-39]. The S content in the MGO/S was tuned in the range of $20-70 \mathrm{wt} \%$.

The CGO/S composite was synthesized via a chemical route. The rGO was dispersed in the sodium polysulfide $\left(\mathrm{Na}_{2} \mathrm{~S}_{x}\right)$ aqueous solution with a $5 \mathrm{wt} \%$ cetrimonium bromide $(\mathrm{CTAB})$ and sonicated for $4 \mathrm{~h}$ to ensure complete dispersion. Afterwards, $2 \mathrm{M}$ acetic acid was slowly titrated into the solution. Acetic acid was chosen for its gentle reaction rate with sodium polysulfide, resulting in a better distribution and finer S particle size. After filtering and washing, the $\mathrm{rGO} / \mathrm{S}$ precipitates were dried under vacuum at $50^{\circ} \mathrm{C}$ for $12 \mathrm{~h}$ and further thermally treated under nitrogen flows at $155^{\circ} \mathrm{C}$ for $12 \mathrm{~h}$. The $\mathrm{S}$ content in the CGO/S powders was tuned between 20 and $70 \mathrm{wt} \%$ by adjusting the volume of the $\mathrm{Na}_{2} \mathrm{~S}_{x}$ solution to the mass of rGO.

2.2. Electrochemical Characterization. The $\mathrm{rGO} / \mathrm{S}$ powders were mixed with $5 \mathrm{wt} \%$ polyvinylidene fluoride (PVdF) binder solution in $\mathrm{N}$-methyl-2-pyrrolidone (NMP) in a $90: 10$ mass ratio. The slurries were applied to aluminum current collectors via a doctor blade and dried at $50^{\circ} \mathrm{C}$ under vacuum for $12 \mathrm{~h}$. The electrode thickness was $120 \mu \mathrm{m}$ on average. The cathode membrane was cut into a disk of $1 \mathrm{~cm}$ diameter with the help of a precision disc cutter (MTI Corp.). The electrode surface densities (active material only) of the $\mathrm{MGO} / \mathrm{S}$ and CGO/S cathodes were, on average, $1.0 \mathrm{mg} / \mathrm{cm}^{2}$.

The rGO/S cathode discs were tested in either Swageloktype cells or button cells (CR2016) with lithium foil as counter electrode. The electrolyte solution was $1 \mathrm{M}$ lithium bis(trifluoromethane)sulfonimide (LiTFSI) in tetraethylene glycol dimethylether (TEGDME) :1,3-dioxolane (DOL) $(3: 7 \mathrm{v} / \mathrm{v})$. The solvents TEGDME and DOL were dehydrated over $4 \AA$ molecular sieves prior to use. Commercial polypropylene membranes were used as separators, having a thickness of $25 \mu \mathrm{m}$ and an average pore size around $30-40 \mathrm{~nm}$. The cells were assembled in an argon-filled glove box (Omni VAC), with a purifying system controlling the moisture content below $0.5 \mathrm{ppm}$. The cells were galvanostatically cycled at a constant $0.05 \mathrm{C}$ or $0.1 \mathrm{C}$ rate on a LAND CT-2001A battery test system at ambient temperature.

2.3. Material Characterizations. TGA was used to determine the sulfur content in the $\mathrm{rGO} / \mathrm{S}$ powders and was performed on a 2050 Thermogravimetric Analyzer (TA Instruments) at temperatures ranging from room temperature to $600^{\circ} \mathrm{C}$ at a ramping rate of $5^{\circ} \mathrm{C} \mathrm{min}$. The thermal stabilities of the $\mathrm{rGO} / \mathrm{S}$ powders were examined by means of DSC (DSC 2010, TA Instruments). The DSC pan was sealed in ambient atmosphere and the temperature range was set from room temperature to $200^{\circ} \mathrm{C}$ at a ramping rate of $5^{\circ} \mathrm{C} \mathrm{min}^{-1}$. The XRD spectral data were collected on a MD-10 Precision Mini $\mathrm{X}$-ray Diffractometer (MTI Corp.) with $\mathrm{Cu} \mathrm{K} \alpha$ radiation, between scattering angles $(2 \theta)$ of 18 and $72^{\circ}$. SEM images were obtained at $20 \mathrm{kV}$ acceleration voltage in secondary electron mode (Topcon Positioning Systems, Inc.).

Raman point spectra and maps were obtained using a LabRamHR 800 system (Horiba Jobin Yvon) equipped with a confocal scanning Raman microscope (High Stability BX41) and a diode-pumped solid-state, frequency-doubled Nd:YAG laser (Laser Quantum) operating at $532 \mathrm{~nm}$ and $15 \mathrm{~mW}$ of power at the sample. The Stokes scattered photons were collected in a $180^{\circ}$ backscattering geometry through a long working distance 100x objective (Olympus) and were captured via a back-illuminated, thermoelectrically cooled, Andor CCD camera $(1,024 \times 256$ pixels). The integration time of each measurement was $10 \mathrm{~s}$, and signals were averaged for three accumulations to improve the spectral clarity. The spot size of the laser in each measurement was $\sim 1 \mu \mathrm{m}^{2}$, and the spectral resolution was $\sim 1 \mathrm{~cm}^{-1}$ under this set-up. Twodimensional spectral maps of the samples were collected by scanning the laser focus over a $10 \mu \mathrm{m} \times 10 \mu \mathrm{m}$ area in a raster fashion, using a step size of $1 \mu \mathrm{m}$. The resulting hyperspectral datasets were imported into MATLAB for further processing via PLS regression analysis. A 32-point bicubic interpolation function was utilized to reduce pixilation of the final chemical images.

\section{Results and Discussion}

Figure 1 presents the XRD profiles of the two different specimens, that is, $\mathrm{MGO} / \mathrm{S}$ and $\mathrm{CGO} / \mathrm{S}$, with $\mathrm{rGO}$ and pristine $S$ powders for comparison. No traces of impurities were found within the dectection limit of the instrument. Elemental $S$ exists in the orthorhombic phase $(\alpha-S)$ (phase group $f d d d$ ). There are no characteristic diffraction peaks for rGO powders, confirming the transition of graphite's $3 \mathrm{D}$ long-range order stacking into $2 \mathrm{D}$ disordered nanosheets as a result of the chemical exfoliation process. In the MGO/S composites, the characteristic $\alpha$-S peaks are clearly observed. This suggests that elemental S crystallites exist freely throughout the composite. The baseline of the XRD peaks around $25^{\circ}$ is raised for $\mathrm{MGO} / \mathrm{S}$ indicating a coexistence of $\mathrm{S}$ and $\mathrm{rGO}$, and inhomogeneity of the composite as others have indicated. In contrast, the XRD pattern of the $\mathrm{CGO} / \mathrm{S}$ nanocomposite reveals no strong diffraction peaks corresponding to elemental S. This suggests either that the S particles exist in an amorphous phase or that the crystallite size has become 


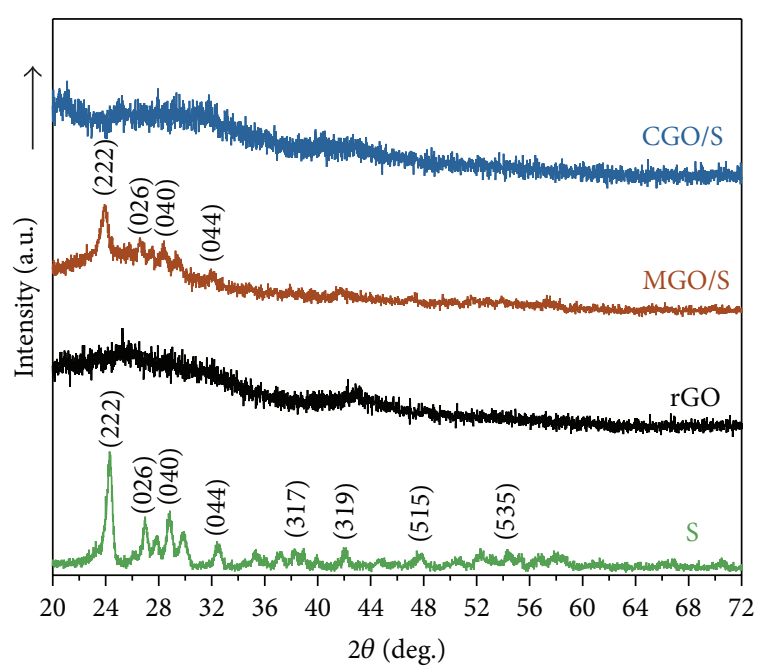

FIGURE 1: XRD patterns of S, rGO, MGO/S, and CGO/S.

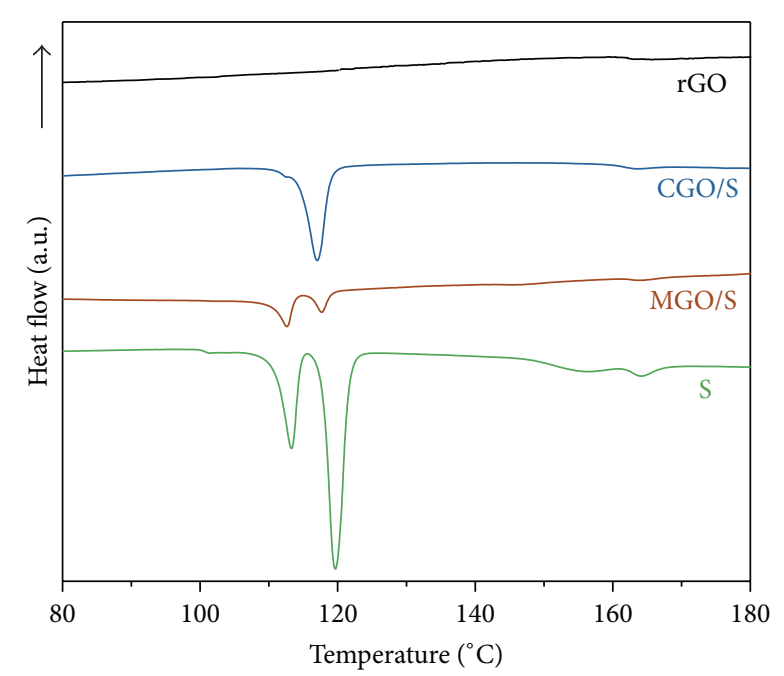

FIgUre 2: DSC profiles of S, rGO, MGO/S, and CGO/S between 80 and $180^{\circ} \mathrm{C}$. Exothermic direction is up.

too small to generate diffraction peaks due to the nanosizing effect of the acetic acid coupled with the surfactant CTAB.

The DSC profiles of $\mathrm{MGO} / \mathrm{S}$ and $\mathrm{CGO} / \mathrm{S}$ specimens are shown in Figure 2. Elemental $\mathrm{S}$ exhibits two endothermic peaks at $113.3^{\circ} \mathrm{C}$ and $119.7^{\circ} \mathrm{C}$. The first peak corresponds to either the solid phase transformation from orthorhombic $(\alpha-S)$ to monoclinic $(\beta-S)$ or the $\alpha$-S phase melting, while the second peak represents the transformation from solid to liquid state ( $\beta$-S melting) [40]. The pristine $S$ peaks are relatively sharp and well resolved. The weak peaks in the range of $157-165^{\circ} \mathrm{C}$ reflect $\lambda$-phase transition and polymerization $[41,42]$. For $\mathrm{MGO} / \mathrm{S}$, all the peaks have reduced in intensity, which correlates linearly with the reduced amount of $\mathrm{S}$ in the composite. It is also observed that the second peak has shifted approximately 2 degrees lower $\left(117.8^{\circ} \mathrm{C}\right)$. The two-degree shift of the liquidation peak of $S$ in the $\mathrm{MGO} / \mathrm{S}$ composite might correlate with the reduction of $\mathrm{S}$ particle size after mechanical grinding. It is interesting to notice that, for the CGO/S nancomposite spectrum, the peak corresponding to the $\alpha$-S melting and/or $\alpha$-S to $\beta$-S transition becomes less detectable. The $\lambda$-transition and polymerization peaks have also diminished significantly. By contrast, the $\beta-S$ phase peak becomes dominant at $117.8^{\circ} \mathrm{C}$. This phenomenon would be attributed to the effective dispersion of the $\beta$-phase sulfur nanoparticles throughout the graphene surface. The confinement of $S$ would result in a masking of the weak phase transition and/or melting occurrence as the capillary action between sulfur and graphene would allow the semiliquidized sulfur to move freely throughtout the graphene structure. The DSC results suggest that the present $S$ phase in CGO/S nanocomposites differentiates from pristine $S$ as well as sulfur presented in $\mathrm{MGO} / \mathrm{S}$.

Figures 3(a) and 3(b) show representative Raman point spectrum and PLS mapping results for $\mathrm{MGO} / \mathrm{S}$. A strong peak ca. $505 \mathrm{~cm}^{-1}$ corresponds to the $A_{1 g}$ symmetric stretching mode of $S$ [43]. Interestingly, this phonon mode experienced a large frequency shift $\left(\sim 35 \mathrm{~cm}^{-1}\right)$ compared to that observed in the bulk S precursor (see the inset in Figure 3(a)). Although unusual, such energetic shifts have been observed for the $A_{1 g}$ mode of $S$ in other similarly prepared GO/S [21]. The presence of only the bulk $\mathrm{S}$ vibrational mode in the MGO/S spectra confirms that the mechanical mixing process only results in the inclusion of bulk $S$ which does not chemically interact with the rGO substrate. The PLS image generated from the hyperspectral data set shows a small, localized inclusion of S. Figures 3(c) and 3(d) show representative Raman point spectrum and PLS mapping results for $\mathrm{CGO} / \mathrm{S}$. A peak centered at $648 \mathrm{~cm}^{-1}$ emerges in nearly all of the acquired pixels. This new peak is likely due to the formation of C-S bonds [21]. In some region, weak peaks centered around $1040 \mathrm{~cm}^{-1}$ representing $\mathrm{O}-\mathrm{S}$ bands are also observed. These extra bonds are probably formed during the chemical deposition of $\mathrm{S}$ onto the rGO surface. Ideally, the chemical approach to synthesizing the CGO/S composite should result in a thin layer of $S$ completely covering the entire GO topology. Indeed, the PLS image generated from the raw hyperspectral data shows a large, nearly homogeneous distribution of chemically incorporated S, which further supports the conclusion of covalently bound $S$ onto the rGO lattice.

Figures 4(a)-4(e) exhibit SEM images of $S$ powder before and after mechanical grinding, $\mathrm{rGO}, \mathrm{MGO} / \mathrm{S}$, and $\mathrm{CGO} / \mathrm{S}$. Comparing Figures 4(a) and 4(b), it is seen that the mechanical grinding condition used in the present experiment has effectively reduced the $S$ particle size from approximately $100-350 \mu \mathrm{m}$ to $2-15 \mu \mathrm{m}$ agglomerates, resembling submicron-sized, fine flakes in appearance. While comparing Figures 4(c) and 4(d), it is apparent that the surface morphology of rGO is altered after mechanical mixing with S. Particularly, the pure rGO nanosheets are curled and have smooth surfaces, whereas the MGO/S surfaces are covered with scattered amounts of S particle agglomerates. The presence of the GO nanosheets has effectively distributed $S$ fine particles and alleviated S agglomeration. The nonuniform distribution of $\mathrm{S}$ in $\mathrm{MGO} / \mathrm{S}$ is also clearly observed, that is, some regions with scarce $S$, while others contain 


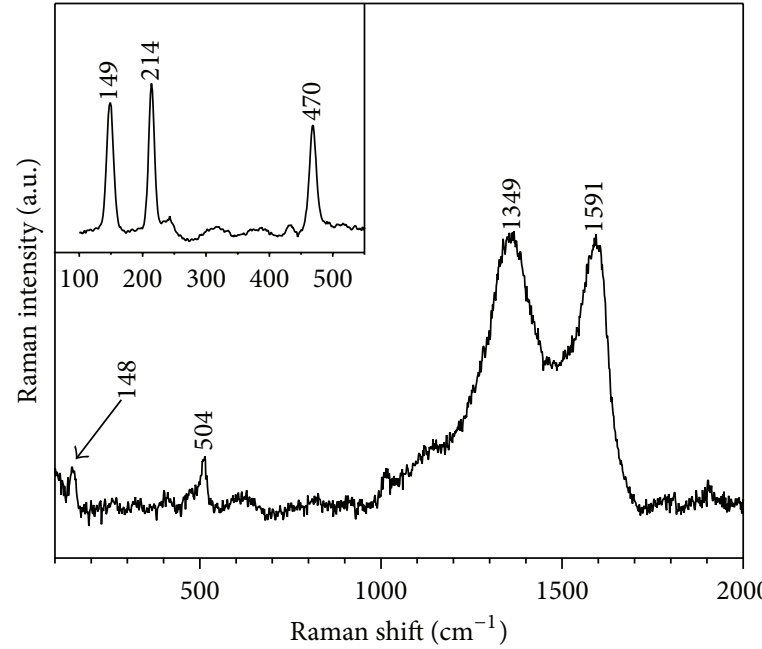

(a)

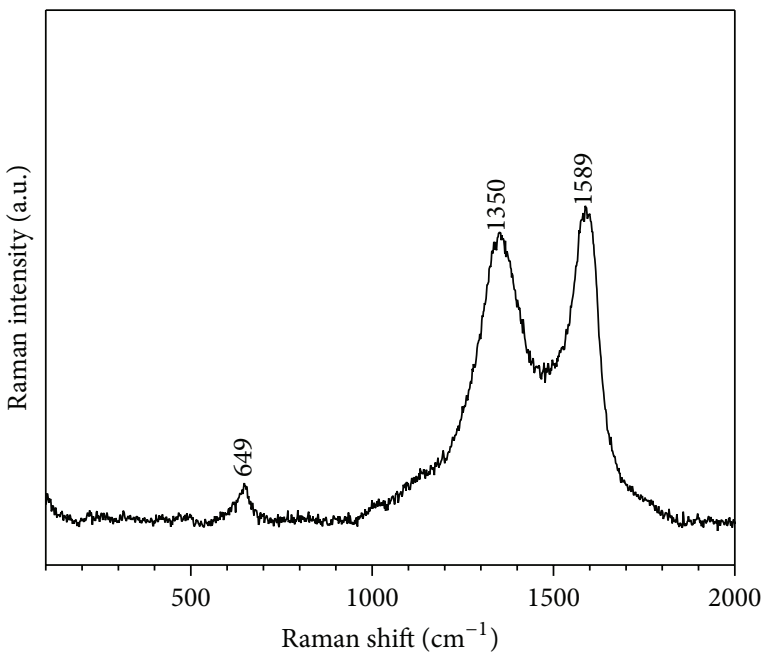

(c)

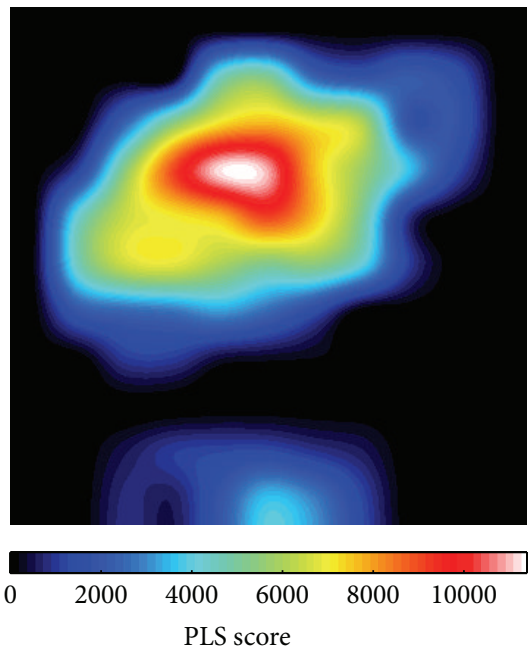

(b)

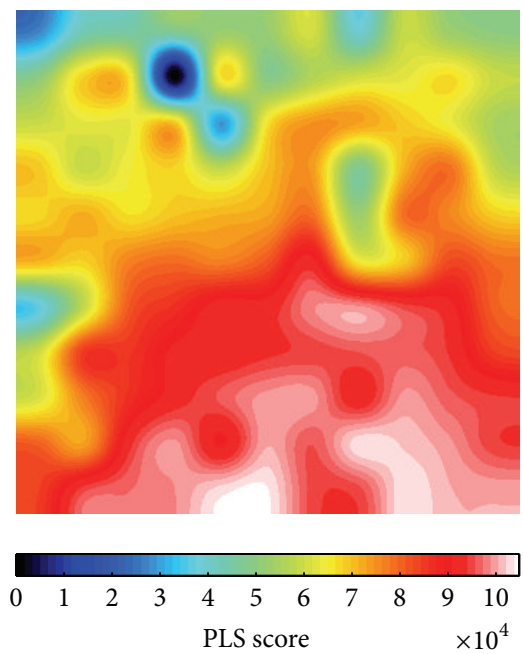

(d)

FIGURE 3: Spontaneous Raman spectra of (a) MGO/S composite and (c) CGO/S nanocomposite. The inset in (a) shows the allowed Raman bands of orthorhombic S. PLS images constructed from the integrated area of the $A_{1}$ mode of pure $S\left(\sim 505 \mathrm{~cm}^{-1}\right)$ for MGO/S (b) and CGO/S (d), respectively.

many S aggregates. The existence of free $\mathrm{S}$ agglomerates and nonhomogeneity is anticipated to have adverse effects on the electrochemical performances. As stated previously, the $S$ aggregates can freely diffuse in the organic solvent and commence the polysulfide shuttle, resulting in capacity loss and cycle fading.

In the CGO/S nanocomposites (see Figure 4(e)), it is difficult to distinguish the $S$ particles from the $\mathrm{rGO}$ nanosheets except that the micrograph is much brighter due to the coverage of the electronically insulating S. Apparently, no $S$ particles or agglomerates are observed, suggesting homogeneous distribution of nanosized S. Moreover, the CGO/S morphology exhibits no significant difference from pristine rGO, maintaining a curly, thin flake-like appearance. This may indicate that the $S$ coverage is very thin. The EDX mapping (see Figures 4(f) and 4(g)) confirms the homogeneous distribution of $S$ throughout the specimen. The homogeneous mixing will enhance the electrical contact area between $S$ and conductive graphene and thereby improve the sulfur utilization and cyclability.

Figure 5(a) shows the 1st and 10th discharge-charge profiles of $\mathrm{MGO} / \mathrm{S}$ and CGO/S composites, both of which contain 50 wt $\%$ rGO content. The intial discharge capacities were 1077 and $1211 \mathrm{mAhg}^{-1} \mathrm{~S}$ for $\mathrm{MGO} / \mathrm{S}$ and $\mathrm{CGO} / \mathrm{S}$, respectively, which correspond to approx. $64.4 \%$ and $72.4 \%$ $\mathrm{S}$ utilization, respectively. The slight difference in the initial capacity arises from the presence of some free isolated $\mathrm{S}$ particles which exhibit poor electronic contact with $\mathrm{rGO}$ and hence the lower utilization. This fact can be correlated with the shape of the initial discharge profiles where there exists the presence of a high-voltage $(2.2-2.4 \mathrm{~V})$ plateau during discharge of the CGO/S electrode. The lack of retention of this high-voltage plateau for the MGO/S electrode suggests poor control of the polysulfide shuttle. Figure 5(b) shows the 


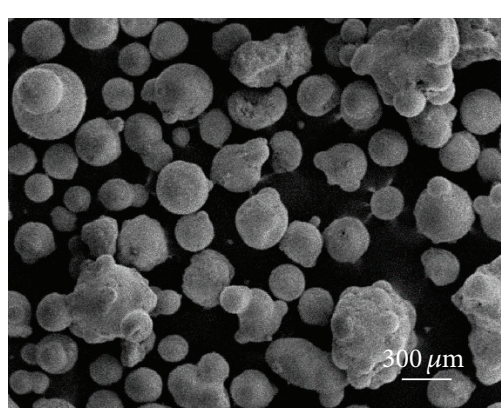

(a)

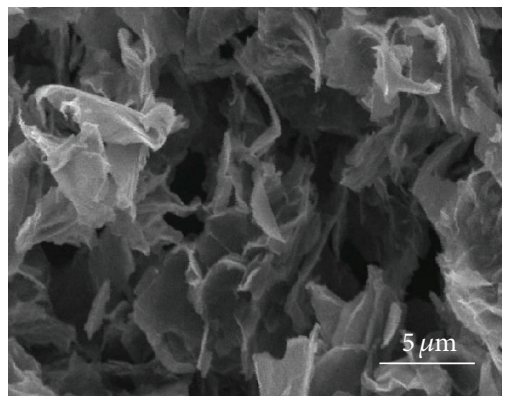

(c)

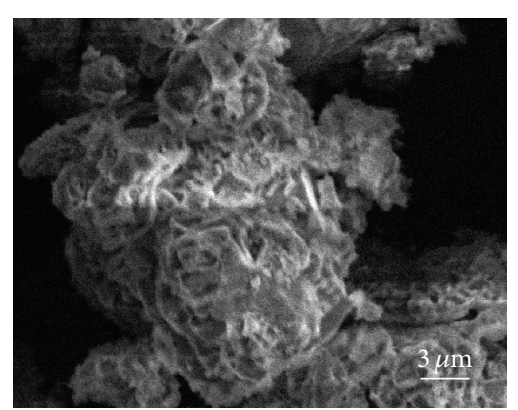

(b)

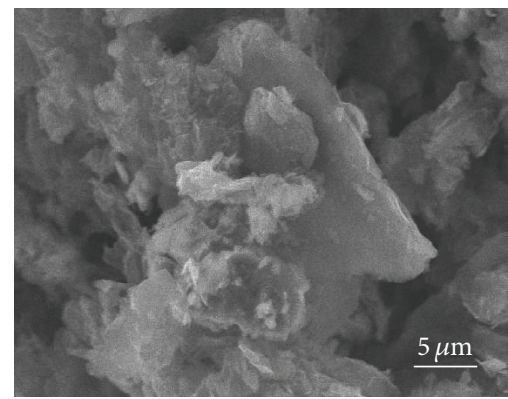

(d)

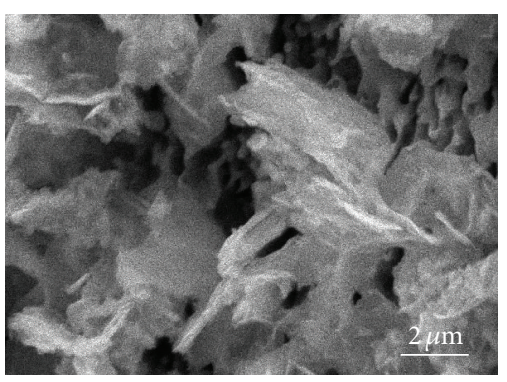

(e)

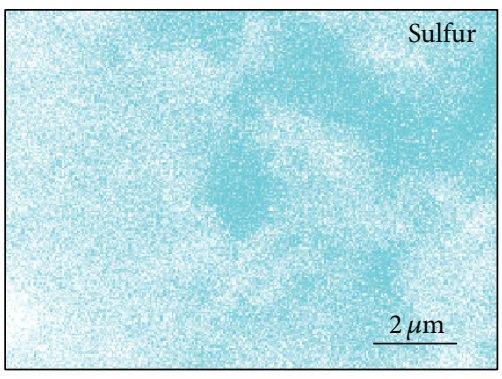

(f)

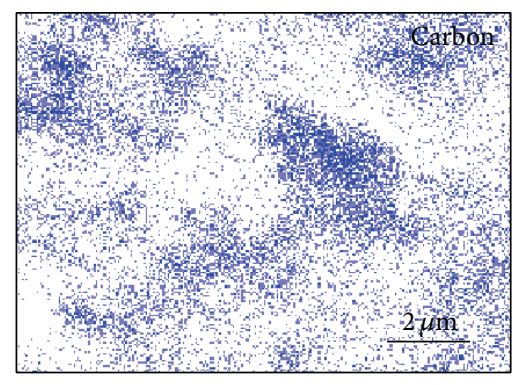

(g)

FIGURE 4: SEM micrographs of colloidal S powder before (a) and after (b) mechanical grinding for 15 min with an agate mortar and pestle, $\mathrm{rGO}(\mathrm{c})$, and MGO/S (d). SEM image obtained from a CGO/S nanocomposite (e) with corresponding EDX maps for S (f) and carbon (g).

fact that the capacity fades rapidly for MGO/S. Upon discharge/charge cycling, the unbonded S particles in $\mathrm{MGO} / \mathrm{S}$ react with lithium to form polysulfides which then readily dissolve into the electrolyte and migrate to the anode. As a result, the MGO/S capacity is reduced to $240 \mathrm{mAh} \mathrm{g}^{-1}$ at the 25 th cycle which is only $22 \%$ retention of its initial capacity. As for CGO/S, due to effective interaction between $S$ and $\mathrm{rGO}$, the capacity retention is improved significantly. At the 25 th cycle, the reverisble capacity is maintained at $640 \mathrm{mAh} / \mathrm{g}$ which is 2.5 times better than that of $\mathrm{MGO} / \mathrm{S}$.

Figures 5(c) and 5(d) plot the reversible capacity (at the 5th cycle) as a function of the rGO percentage. Both the specific capacities in terms of net sulfur and the total electrode composite, that is, $Q_{S}$ and $Q_{T}$, are presented. Compared with $Q_{S}, Q_{T}$ is more practically meaningful in the lithium-battery configuration. In $\mathrm{MGO} / \mathrm{S}, Q_{S}$ is only $100 \mathrm{mAh} / \mathrm{g}$ at $20 \mathrm{wt} \% \mathrm{rGO}$ but reaches up to $900 \mathrm{mAh} / \mathrm{g}$ with $75 \mathrm{wt} \% \mathrm{rGO}$. The high value in the latter case lies in the improvement of electrical conductance and contact and hence the sulfur utilization. In the range of $40-50 \%$, the $Q_{S}$ changes insignificantly in $\mathrm{MGO} / \mathrm{S}$ suggesting the percolation threshold. As for CGO/S, both $Q_{S}$ and $Q_{T}$ values at each composition increased by $100-200 \mathrm{mAh} / \mathrm{g}$ throughout the entire range. Additionally, the general trend shows the continuous increase of $Q_{S}$ with the rGO content. These phenomena are attributed to the effective nanosizing of the $S$ particles and enhanced the electrical contact between $S$ and rGO. It is noteworthy that no percolation threshold is observed for $\mathrm{CGO} / \mathrm{S}$ in the experimental composition range. The values of $Q_{T}$ decrease continuously with the rGO content because $\mathrm{rGO}$ is an inactive conponent for lithium storage. The maximum $Q_{T}$ reaches $400 \mathrm{mAh} / \mathrm{g}$ which is 2-3 times the cathode matrials like $\mathrm{LoCoO}_{2}$ and $\mathrm{LiFePO}_{4}$.

Although our material characterization techniques have indicated a homogeneous dispersion of $S$ throughout the $\mathrm{rGO}$ host structure as well as the formation of a covalent bond between $\mathrm{C}$ and $\mathrm{S}$, the liquid electrolyte used in this research was still capable of penetrating into accessible voids within the $\mathrm{CGO} / \mathrm{S}$ microstructure and inducing the polysulfide shuttle. Consequently, the first Coulombic efficiency of the 


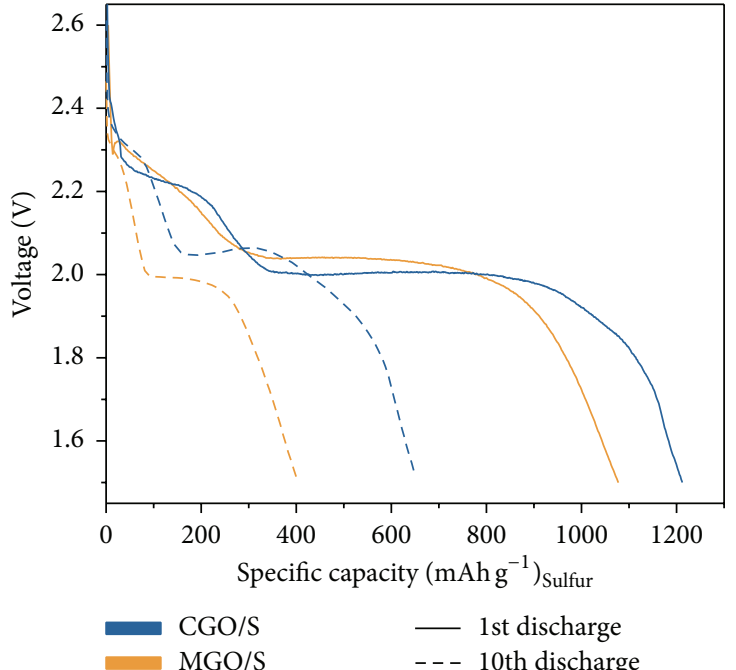

(a)

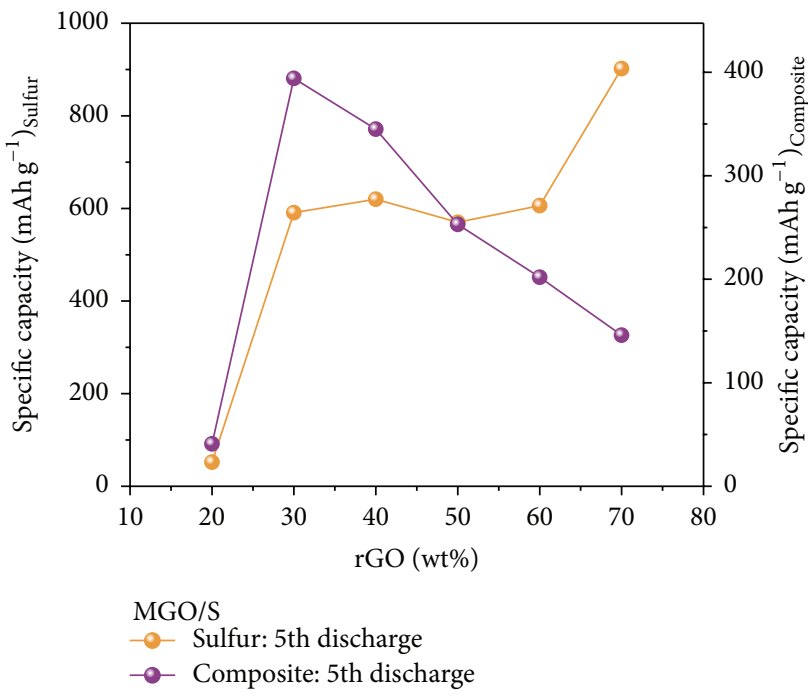

(c)

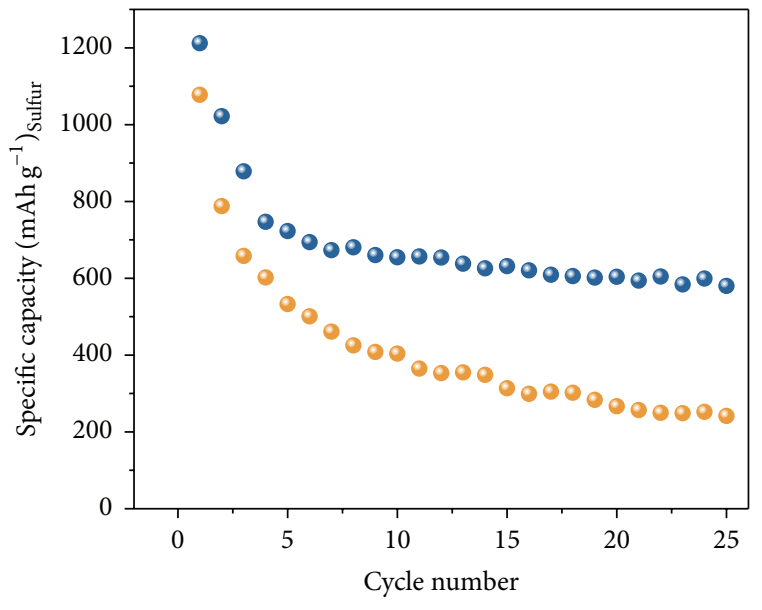

- $\mathrm{CGO} / \mathrm{S}$

- $\mathrm{MGO} / \mathrm{S}$

(b)

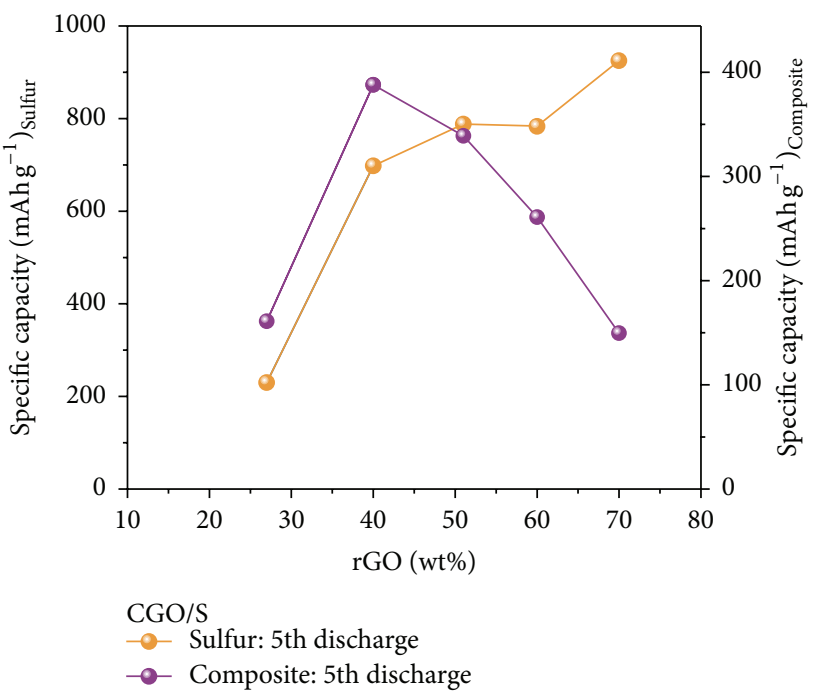

(d)

FIGURE 5: Voltage profiles of CGO/S and MGO/S at the 1st and 10th discharge cycle (a), and the corresponding cycle life plot (b). Experiments were conducted at a constant $0.05 \mathrm{C}$ rate at room temperature $\left(1 \mathrm{C}=1672 \mathrm{mAh} \mathrm{g}^{-1}\right)$. Specific capacity as a function of rGO wt\% for MGO/S (c) and CGO/S (d). The left $y$-axis is based on the specific capacity of S, while the right $y$-axis is based on the mass of the entire composite (i.e., $\mathrm{S}, \mathrm{rGO}$, and binder).

CGO/S cathode in $1 \mathrm{M}$ LiTFSI-TEGMDE/DOL $(30: 70 \mathrm{v} / \mathrm{v})$ electrolyte was only $79 \%$ and the effects of this process were manifested in the significant capacity fade observed during the first five cycles. As elucidated by this work, C-S composite enhancements alone offer limited room for the improvement of battery performance unless an appropriate electrolyte is used, and liquid electrolytes will inevitably lead to some extent of active material dissolution and capacity fade upon cycling.

\section{Conclusions}

Homogenous distribution of amorphous/nanocrystalline sulfur was achieved throughout a reduced graphene oxide matrix by utilizing a one-step chemical synthesis route. The resulting CGO/S electrode consistently exhibited enhanced sulfur utilization and improved cyclability compared to the mechanically mixed composite containing the same amount of sulfur. This was attributed to the enhanced interaction between $\mathrm{rGO}$ and nanosized $\mathrm{S}$ as well as increased electrical contact. The CGO/S nanocomposites showed no percolation threshold within the experimental composition range (30-70 wt $\%$ rGO) and the maximum specific capacity per total electrode composite reached $400 \mathrm{mAh} / \mathrm{g}$ which is 2-3 times the cathode matrials like $\mathrm{LoCoO}_{2}$ and $\mathrm{LiFePO}_{4}$.

\section{Conflict of Interests}

The authors declare that there is no conflict of interests regarding the publication of this paper. 


\section{References}

[1] H. Yamin and E. Peled, "Electrochemistry of a nonaqueous lithium/sulfur cell," Journal of Power Sources, vol. 9, no. 3-4, pp. 281-287, 1983.

[2] Y. Yang, G. Zheng, and Y. Cui, "Nanostructured sulfur cathodes," Chemical Society Reviews, vol. 42, no. 7, pp. 3018-3032, 2013.

[3] S. Evers and L. F. Nazar, "New approaches for high energy density lithium-sulfur battery cathodes," Accounts of Chemical Research, vol. 46, no. 5, pp. 1135-1143, 2013.

[4] H. S. Ryu, H. J. Ahn, K. W. Kim, J. H. Ahn, J. Y. Lee, and E. J. Cairns, "Self-discharge of lithium-sulfur cells using stainlesssteel current-collectors," Journal of Power Sources, vol. 140, no. 2, pp. 365-369, 2005.

[5] S.-E. Cheon, J.-H. Cho, K.-S. Ko et al., "Structural factors of sulfur cathodes with poly(ethylene oxide) binder for performance of rechargeable lithium sulfur batteries," Journal of the Electrochemical Society, vol. 149, no. 11, pp. A1437-A1441, 2002.

[6] M. Barghamadi, A. Kapoor, and C. Wen, "A review on Li$\mathrm{S}$ batteries as a high efficiency rechargeable lithium battery," Journal of the Electrochemical Society, vol. 160, no. 8, pp. A1256A1263, 2014.

[7] D.-W. Wang, Q. Zeng, G. Zhou et al., "Carbon-sulfur composites for Li-S batteries: status and prospects," Journal of Materials Chemistry A, vol. 1, no. 33, pp. 9382-9394, 2013.

[8] X. Ji, K. T. Lee, and L. F. Nazar, "A highly ordered nanostructured carbon-sulphur cathode for lithium-sulphur batteries," Nature Materials, vol. 8, no. 6, pp. 500-506, 2009.

[9] Y. Yang, M. T. McDowell, A. Jackson, J. J. Cha, S. S. Hong, and Y. Cui, "New nanostructured $\mathrm{Li}_{2} \mathrm{~S} /$ Silicon rechargeable battery with high specific energy," Nano Letters, vol. 10, no. 4, pp. 14861491, 2010.

[10] S. Xin, L. Gu, N.-H. Zhao et al., "Smaller sulfur molecules promise better lithium-sulfur batteries," Journal of the American Chemical Society, vol. 134, no. 45, pp. 18510-18513, 2012.

[11] G. Zheng, Y. Yang, J. J. Cha, S. S. Hong, and Y. Cui, "Hollow carbon nanofiber-encapsulated sulfur cathodes for high specific capacity rechargeable lithium batteries," Nano Letters, vol. 11, no. 10, pp. 4462-4467, 2011.

[12] L. Ji, M. Rao, S. Aloni, L. Wang, E. J. Cairns, and Y. Zhang, "Porous carbon nanofiber-sulfur composite electrodes for lithium/sulfur cells," Energy and Environmental Science, vol. 4, no. 12, pp. 5053-5059, 2011.

[13] W. Ahn, K.-B. Kim, K.-N. Jung, K.-H. Shin, and C.-S. Jin, "Synthesis and electrochemical properties of a sulfur-multi walled carbon nanotubes composite as a cathode material for lithium sulfur batteries," Journal of Power Sources, vol. 202, pp. 394-399, 2012.

[14] T. Lin, Y. Tang, Y. Wang et al., "Scotch-tape-like exfoliation of graphite assisted with elemental sulfur and graphene-sulfur composites for high-performance lithium-sulfur batteries," Energy \& Environmental Science, vol. 6, no. 4, pp. 1283-1290, 2013.

[15] F. Zhang, Y. Dong, Y. Huang, G. Huang, X. Zhang, and L. Wang, "Preparation and performance of a sulfur/graphene composite for rechargeable lithium-sulfur battery," Journal of Physics: Conference Series, vol. 339, no. 1, Article ID 12003, 2012.

[16] Y.-X. Wang, L. Huang, L.-C. Sun et al., "Facile synthesis of a interleaved expanded graphite-embedded sulphur nanocomposite as cathode of $\mathrm{Li}-\mathrm{S}$ batteries with excellent lithium storage performance," Journal of Materials Chemistry, vol. 22, no. 11, pp. 4744-4750, 2012.

[17] N. Li, M. Zheng, H. Lu et al., "High-rate lithium-sulfur batteries promoted by reduced graphene oxide coating," Chemical Communications, vol. 48, no. 34, pp. 4106-4108, 2012.

[18] B. Ding, C. Yuan, L. Shen et al., "Chemically tailoring the nanostructure of graphene nanosheets to confine sulfur for high-performance lithium-sulfur batteries," Journal of Materials Chemistry A, vol. 1, no. 4, pp. 1096-1101, 2013.

[19] H. Wang, Y. Yang, Y. Liang et al., "Graphene-wrapped sulfur particles as a rechargeable lithium-sulfur battery cathode material with high capacity and cycling stability," Nano Letters, vol. 11, no. 7, pp. 2644-2647, 2011.

[20] J.-Z. Wang, L. Lu, M. Choucair, J. A. Stride, X. Xu, and H.-K. Liu, "Sulfur-graphene composite for rechargeable lithium batteries," Journal of Power Sources, vol. 196, no. 16, pp. 7030-7034, 2011.

[21] S. Evers and L. F. Nazar, "Graphene-enveloped sulfur in a one pot reaction: a cathode with good coulombic efficiency and high practical sulfur content," Chemical Communications, vol. 48, no. 9, pp. 1233-1235, 2012.

[22] Z. Wei, J. Chen, L. Qin, A. Nemage, M. Zheng, and Q. Dong, "Two-step hydrothermal method for synthesis of sulfurgraphene hybrid and its application in lithium sulfur batteries," Journal of the Electrochemical Society, vol. 159, no. 8, pp. A1236A1239, 2012.

[23] H. Sun, G.-L. Xu, Y.-F. Xu et al., "A composite material of uniformly dispersed sulfur on reduced graphene oxide: aqueous one-pot synthesis, characterization and excellent performance as the cathode in rechargeable lithium-sulfur batteries," Nano Research, vol. 5, no. 10, pp. 726-738, 2012.

[24] M.-S. Park, J.-S. Yu, K. J. Kim et al., "One-step synthesis of a sulfur-impregnated graphene cathode for lithium-sulfur batteries," Physical Chemistry Chemical Physics, vol. 14, no. 19, pp. 6796-6804, 2012.

[25] Y. Cao, X. Li, I. A. Aksay et al., "Sandwich-type functionalized graphene sheet-sulfur nanocomposite for rechargeable lithium batteries," Physical Chemistry Chemical Physics, vol. 13, no. 17, pp. 7660-7665, 2011.

[26] L. Ji, M. Rao, H. Zheng, L. Zhang, O. Y. Li, and W. Duan, "Graphene oxide as a sulfur immobilizer in high performance," Journal of the American Chemical Society, vol. 133, Article ID 1852218525, pp. 18522-18525, 2011.

[27] F.-F. Zhang, X.-B. Zhang, Y.-H. Dong, and L.-M. Wang, "Facile and effective synthesis of reduced graphene oxide encapsulated sulfur via oil/water system for high performance lithium sulfur cells," Journal of Materials Chemistry, vol. 22, no. 23, pp. 1145211454, 2012.

[28] L. Zhang, L. Ji, P.-A. Glans, Y. Zhang, J. Zhu, and J. Guo, "Electronic structure and chemical bonding of a graphene oxide-sulfur nanocomposite for use in superior performance lithium-sulfur cells," Physical Chemistry Chemical Physics, vol. 14, no. 39, pp. 13670-13675, 2012.

[29] M. S. Dresselhaus and G. Dresselhaus, "Intercalation compounds of graphite," Advances in Physics, vol. 51, no. 1, pp. 1-186, 2002.

[30] S. Bourdo, Z. Li, A. S. Biris, F. Watanabe, T. Viswanathan, and I. Pavel, "Structural, electrical, and thermal behavior of graphitepolyaniline composites with increased crystallinity," Advanced Functional Materials, vol. 18, no. 3, pp. 432-440, 2008. 
[31] M. A. Pimenta, G. Dresselhaus, M. S. Dresselhaus, L. G. Cançado, A. Jorio, and R. Saito, "Studying disorder in graphitebased systems by Raman spectroscopy," Physical Chemistry Chemical Physics, vol. 9, no. 11, pp. 1276-1291, 2007.

[32] L. G. Cançado, M. A. Pimenta, B. R. A. Neves et al., "Anisotropy of the Raman spectra of nanographite ribbons," Physical Review Letters, vol. 93, no. 4, Article ID 047403, 2004.

[33] M. Barker and W. Rayens, "Partial least squares for discrimination," Journal of Chemometrics, vol. 17, no. 3, pp. 166-173, 2003.

[34] K. P. J. Williams and N. J. Everall, "Use of micro Raman spectroscopy for the quantitative determination of polyethylene density using partial least-squares calibration," Journal of Raman Spectroscopy, vol. 26, no. 6, pp. 427-433, 1995.

[35] D. Zhang, C. Ortiz, Y. Xie, V. J. Davisson, and D. Ben-Amotz, "Detection of the site of phosphorylation in a peptide using Raman spectroscopy and partial least squares discriminant analysis," Spectrochimica Acta A: Molecular and Biomolecular Spectroscopy, vol. 61, no. 3, pp. 471-475, 2005.

[36] S. Wold, M. Sjöström, and L. Eriksson, "PLS-regression: a basic tool of chemometrics," Chemometrics and Intelligent Laboratory Systems, vol. 58, no. 2, pp. 109-130, 2001.

[37] W. S. Hummers Jr. and R. E. Offeman, "Preparation of graphitic oxide," Journal of the American Chemical Society, vol. 80, no. 6, p. 1339, 1958.

[38] W. Gao, L. B. Alemany, L. Ci, and P. M. Ajayan, "New insights into the structure and reduction of graphite oxide," Nature Chemistry, vol. 1, no. 5, pp. 403-408, 2009.

[39] S. L. Cheekati, Z. Yao, and H. Huang, "The impacts of graphene nanosheets and manganese valency on lithium storage characteristics in graphene/manganese oxide hybrid anode," Journal of Nanomaterials, vol. 2012, Article ID 819350, 10 pages, 2012.

[40] B. Meyer, "Elemental sulfur," Chemical Reviews, vol. 76, no. 3, pp. 367-388, 1976.

[41] V. F. Kozhevnikov, W. B. Payne, J. K. Olson, C. L. McDonald, and C. E. Inglefield, "Physical properties of sulfur near the polymerization transition," Journal of Chemical Physics, vol. 121, no. 15, pp. 7379-7386, 2004.

[42] T. Scopigno, S. N. Yannopoulos, F. Scarponi, K. S. Andrikopoulos, D. Fioretto, and G. Ruocco, "Origin of the $\lambda$ transition in liquid sulfur," Physical Review Letters, vol. 99, no. 2, Article ID 025701, 2007.

[43] A. T. Ward, "Raman spectroscopy of sulfur, sulfur-selenium, and sulfur-arsenic mixtures," The Journal of Physical Chemistry, vol. 72, no. 12, pp. 4133-4139, 1968. 

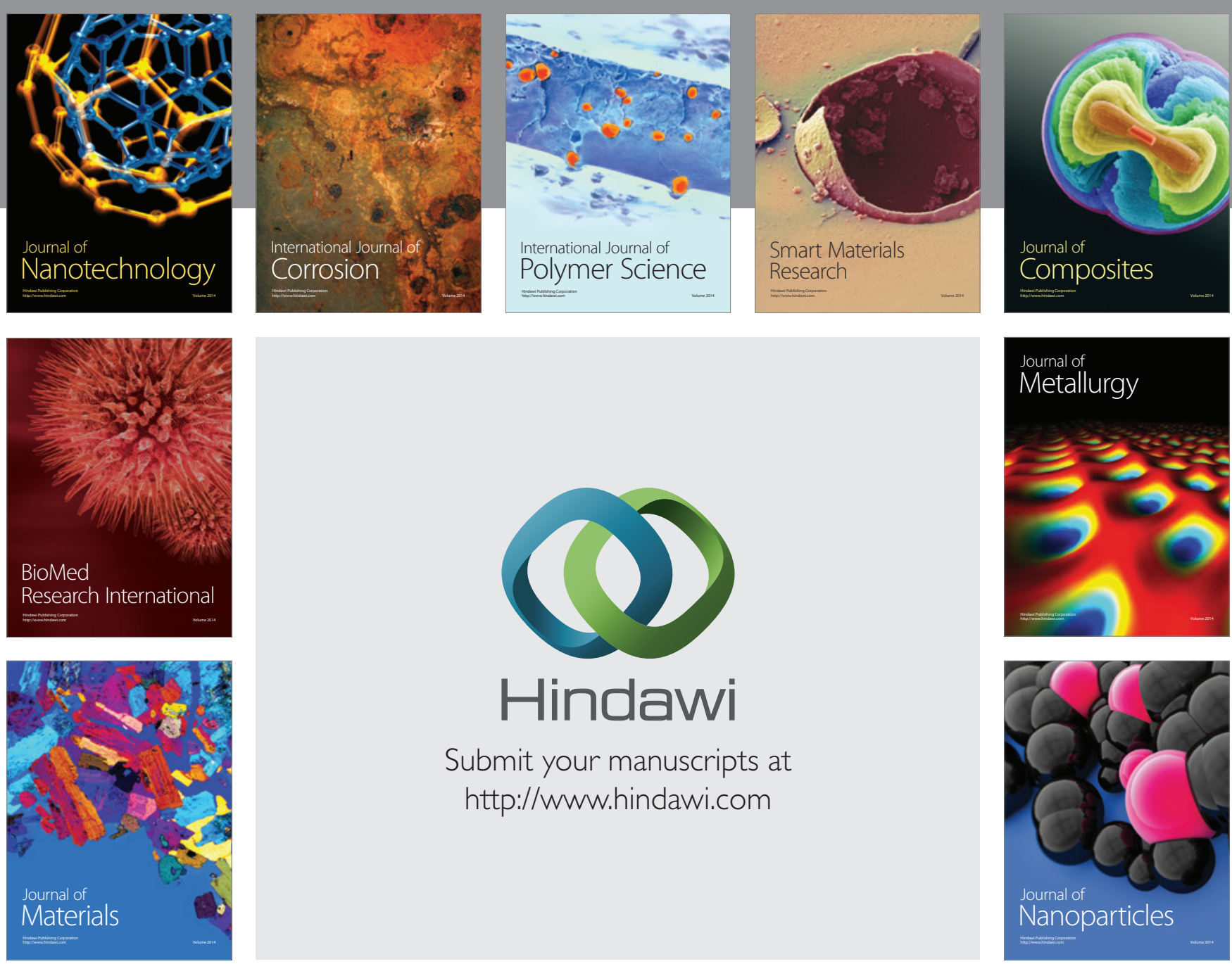

Submit your manuscripts at http://www.hindawi.com
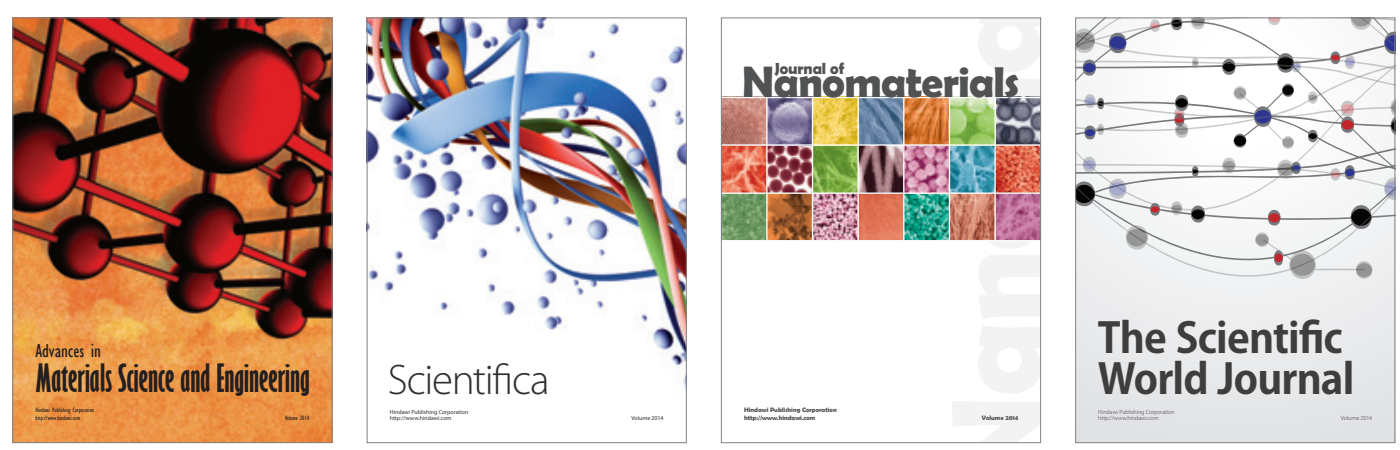

\section{The Scientific World Journal}
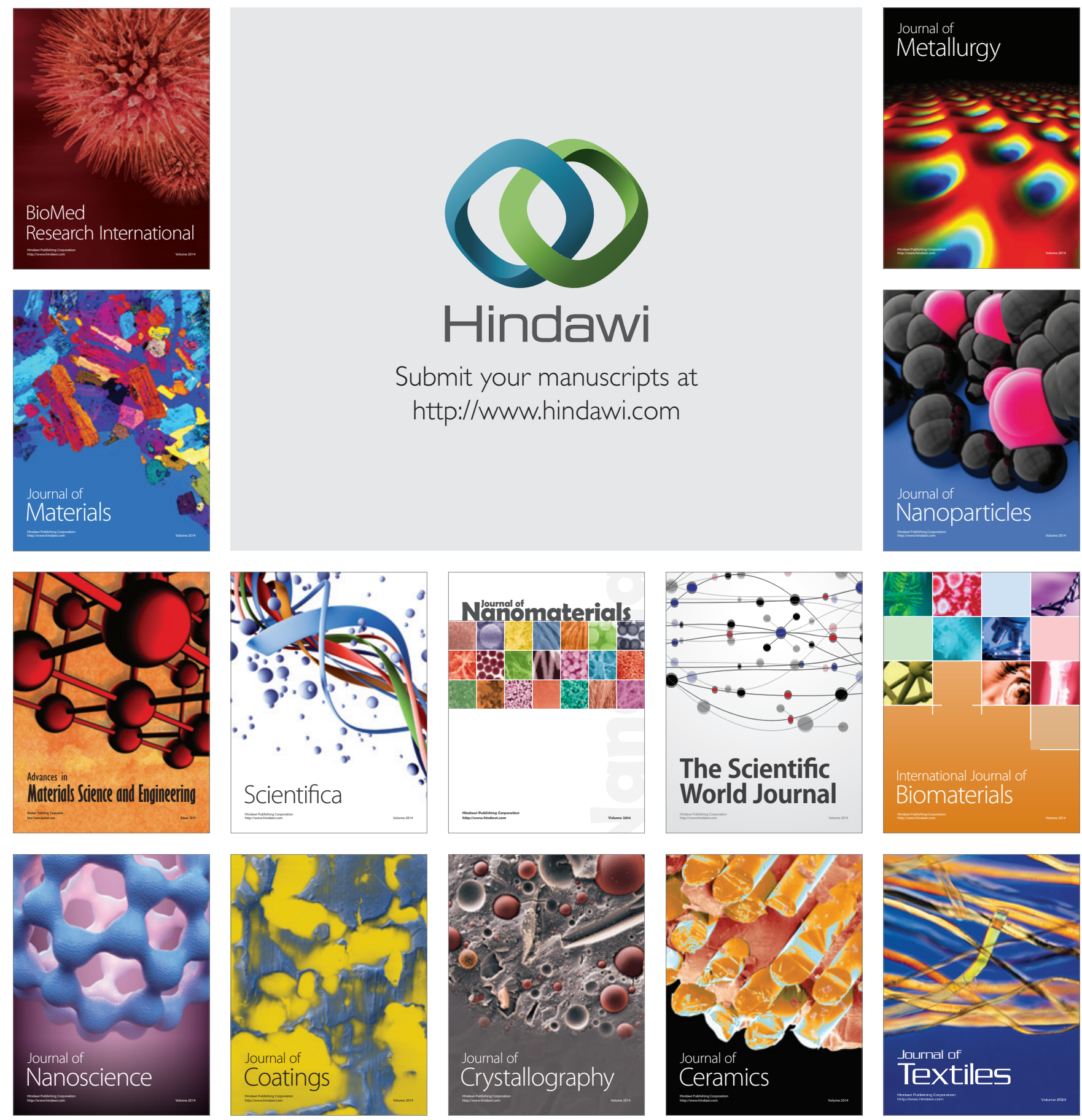